\title{
Current and Emerging Approaches for Pain Management in Hemophilic Arthropathy
}

\author{
Roberta Gualtierotti (D) - Francesco Tafuri · Sara Arcudi • \\ Pier Luigi Solimeno · Jacopo Acquati · Laura Landi · Flora Peyvandi
}

Received: August 7, 2021 / Accepted: December 7, 2021 / Published online: January 12, 2022

(C) The Author(s) 2022

\begin{abstract}
Introduction: Hemophilia is an inherited bleeding hematological disorder characterized by the partial or complete deficiency of clotting factor VIII or IX. Hemophilic arthropathy is the consequence of repeated joint bleeding (hemarthrosis) and its management is based on the prevention of acute bleeding through the administration of the deficient clotting factor concentrate or non-factor therapies. In addition, the management of acute and chronic pain is pivotal in hemophilic arthropathy in order to restore function and allow rehabilitation of the joint.
\end{abstract}

R. Gualtierotti $(\bowtie) \cdot$ F. Peyvandi

Università degli Studi di Milano, Dipartimento di Fisiopatologia e Medicina dei Trapianti, Via Pace, 9, 20122 Milan, Italy

e-mail: roberta.gualtierotti@unimi.it

R. Gualtierotti · F. Tafuri · S. Arcudi · F. Peyvandi Fondazione IRCCS Ca' Granda Ospedale Maggiore Policlinico, Medicina Interna - Emostasi e Trombosi e Centro Emofilia e Trombosi, Milan, Italy

P. L. Solimeno $\cdot$ J. Acquati

Fondazione IRCCS Ca' Granda Ospedale Maggiore Policlinico, Ortopedia e Traumatologia, Milan, Italy

L. Landi

Fondazione IRCCS Ca' Granda Ospedale Maggiore Policlinico, Anestesia e Terapia Intensiva DonnaBambino, Milan, Italy
Methods: We conducted a qualitative review of the literature regarding current and emerging strategies for pain treatment in hemophilic arthropathy. This review considers systemic and local pharmacological and non-pharmacological interventions for acute and chronic pain management.

Results: In hemophilic arthropathy, pain management is based on analgesics such as paracetamol, which represents the first choice for acute and chronic pain in adults and children, in association with opioids for adults. Non-steroidal anti-inflammatory drugs inhibit platelet function, so that the currently preferred drugs are short courses of cyclooxygenase 2 inhibitors. Local treatment with intra-articular injections of corticosteroids is an option for refractory cases and physiotherapy has an important role after hemarthrosis and for the long-term management of chronic pain for both pediatric and adult patients.

Conclusions: The management of pain in hemophilia requires more standardization. Meanwhile, the safest drugs should be used at the lowest effective dosage and for periods as short as possible. For the non-pharmacological management of pain in these patients, a multidisciplinary team including hematologists, orthopedic surgeons, rheumatologists, and physiotherapists is warranted.

Keywords: Acute pain; Chronic pain; Hemarthrosis; Hemophilic arthropathy 


\section{Key Summary Points}

Why carry out this study?

Notwithstanding the fact that the care of hemophilia patients has improved dramatically over the last decade, some of them still experience joint bleeding.

Hemarthrosis is associated with acute pain and its recurrence leads to hemophilic arthropathy, which in turn leads to disability and chronic pain.

This review considers systemic and local pharmacological and nonpharmacological interventions for the management of acute and chronic pain in hemophilia.

\section{What was learned from the study?}

Acute and chronic pain in patients with hemophilia requires a multidisciplinary approach.

The management of pain due to hemophilic arthropathy still requires standardization. Meanwhile, the safest drugs should be used at the lowest effective dosage and for periods as short as possible.

\section{INTRODUCTION}

Hemophilia is a rare, X-linked inherited bleeding disorder characterized by the deficiency of coagulation factor VIII (FVIII) in hemophilia A and FIX in hemophilia $\mathrm{B}$. The prevalence of hemophilia $\mathrm{A}$ is estimated to be around 1 in 5000-10,000 males, and that of hemophilia B 1 in 25,000-30,000 males. Around 30\% of new cases have no known familial history $[1,2]$. As a consequence of the hemorrhagic diathesis, the clinical manifestations of hemophilia are represented by recurrent bleeding, whose severity is generally directly correlated with the degree of decrease of the deficient clotting factor.
Patients with severe hemophilia (factor level $<$ $1 \%$ ) usually suffer from spontaneous bleedings. In patients with mild hemophilia (factor level $>5 \%$ ), bleeding mostly occurs after major trauma or surgery. Patients with moderate hemophilia (2-5\% FVIII activity) have an intermediate clinical phenotype, but arthropathy may be observed in a relevant proportion of them [3].

Spontaneous musculoskeletal bleeding accounts for $80 \%$ of all episodes, particularly in synovial joints and muscles, whereas cerebral and mucosal hemorrhages are less frequently $[4,5]$. Ankles, knees, and elbows are the most commonly affected joints, and those undergoing three or more spontaneous bleeds over a 6-month period are defined target joints [6]. Recurrent joint bleeding (hemarthrosis) causes synovial hypertrophy and hemosiderin deposition in macrophage-like synovial cells, as a consequence of the intra-articular shedding of blood and iron. An inflammatory process develops and angiogenesis leads to the formation of fragile vessels, thus exposing the synovial membrane to further bleeding in a vicious circle [7]. Subsequently, fibrosis of the subsynovial layer occurs and the production of proteolytic enzymes has a destructive effect on both cartilage and bone. Thus, patients with severe hemophilia often develop a chronic arthropathy that presents with intermediate characteristics between inflammatory arthropathies such as rheumatoid arthritis and degenerative arthropathies such as osteoarthritis [8].

Despite the fact that hemophilia care improved dramatically over the last decade thanks to the introduction of recombinant factors with extended half-life and non-factor therapies, patients still experience arthropathy, which leads to disability and eventually to the early need of joint replacement, reduced quality of life, and work and school absenteeism, thus causing a relevant burden of illness [9-14]. One of the main unsolved problems for patients with arthropathy is chronic pain, which requires a multidisciplinary approach [15]. In this review, we provide an overview of the systemic and local hematological and non-hematological strategies for pain management, not only at the time of acute joint bleeding but also 
in the course of chronic arthropathy. This article is based on previously conducted studies and does not involve any new studies of human or animal subjects performed by any of the authors.

\section{MANAGEMENT OF ACUTE JOINT BLEEDING}

Acute clinical signs and symptoms of hemarthrosis include some or all of the following: 'aura', i.e., an unusual sensation of tingling inside a joint, pain, swelling, warmth of the skin over the joint, decreased range of motion or full loss of function [6]. One of the biggest issues for patients with hemophilia is the need for a better self-differentiation between acute hemarthrosis and chronic joint pain, and it is still a matter of debate whether or not they are able to distinguish the two conditions $[16,17]$. In fact, significant discrepancies have been reported by means of musculoskeletal ultrasound findings between patient and physician classification of pain as due to bleeding or non-bleeding [18]. Moreover, pain acceptance is pivotal in the process of adjustment to chronic pain, which involves the acceptance that trying to avoid or control pain can be counterproductive and that activity engagement means continuing with life activities despite pain [19].

\section{Bleeding Control}

The primary aim of the management of acute hemarthrosis is to achieve, as soon as possible, the control of bleeding. Factor replacement is the mainstay and should be administered ideally as soon as possible and continued over the next few days. Adequate patient education and empowerment is pivotal, and envisages the ability to promptly recognize bleeding, timely self-administer the deficient factor or other therapeutic products such as by-passing agents and to contact the hemophilia treatment center (HTC) that should keep a record of the bleeds and their management [20]. The therapeutic target of early/moderate bleeds should be plasma factor levels of $40-60 \mathrm{UI} / \mathrm{dl}$, which can be achieved in non-inhibitor patients by means of a dosage of $25-30 \mathrm{UI} / \mathrm{kg}$ of factor VIII in severe hemophilia A and 40-60 UI/kg of FIX in severe hemophilia B [20]. Patients with inhibitors should be treated with the activated prothrombin complex concentrate aPCC (50-100 IU/kg) or recombinant activated factor VIIa (rFVIIa) $(270 \mu \mathrm{g} / \mathrm{kg}$ as a single dose or $90 \mu \mathrm{g} / \mathrm{kg} \mathrm{2-3}$ hourly). Repeated doses can be administered if the first is ineffective but the total daily dose of aPCC should not exceed $200 \mathrm{IU} / \mathrm{kg}$ in order to decrease the risk of thrombosis. Emicizumab is a humanized monoclonal antibody that given subcutaneously mimics the activity of FVIII by binding activated FIX to FX and is thus licensed in patients with severe hemophilia A with or without inhibitors [21, 22]. Cases of thrombotic microangiopathy and other thrombotic events have been reported when a cumulative amount of $>100 \mathrm{IU} / \mathrm{kg}$ of aPCC was concomitantly administered for $24 \mathrm{~h}$ or more to patients on emicizumab prophylaxis [21]. These observations led to the following management guidelines [23, 24]. For patients with inhibitors, $90-120 \mu \mathrm{g} / \mathrm{kg}$ of rFVIIa should be administered and repeated every $2-4 \mathrm{~h}$. Only in case of severe hemorrhages not responsive to rFVIIa and in the presence of a high-titer inhibitor $(>5 \mathrm{BU} /$ $\mathrm{ml})$, aPCC at the initial dose $\leq 50 \mathrm{IU} / \mathrm{kg}$ may be administered under medical supervision. If this dose of aPCC is insufficient to control bleeding, repeated low doses of aPCC can be administered every 8-12 $\mathrm{h}$ within a total dose $<100 \mathrm{IU} / \mathrm{kg}$ in $24 \mathrm{~h}$ in order to reduce the risk of thrombotic complications. The platelet count, fibrinogen, and D-dimer levels should be checked in order to exclude and prevent a hypercoagulable state and the related risk of thrombosis [21].

\section{Non-hematological Treatment}

In addition to factor replacement, conventional management of joint bleeding envisages the implementation of protection, rest, ice, compression, and limb elevation with the goal to decrease pain, inflammation, and ultimately stop bleeding [25-27]. It has been debated whether or not cryotherapy may delay clot 
formation by interacting with the coagulation system, beside the fact that ice has a vasoconstricting effect and thus it may help to reduce swelling and pain. Cold application should be implemented only for brief time periods such as for $10 \mathrm{~min}$ every $2 \mathrm{~h}$ [28]. Even though aspiration of blood from the joints (arthrocentesis) may lead to the rapid resolution of inflammation, the benefits of this procedure remain controversial due to a lack of solid evidence on the prevention of long-term damage. Indeed, preclinical data, in vitro studies, and animal models showed that a shortened exposure to blood may decrease cartilage damage [29, 30], and observational studies support the role of joint aspiration in accelerating recovery after hemarthrosis [31-33]. However, no randomized clinical trials are available. The risk of infection or recurrent bleeding increases with this procedure and long-term data are not available. In case of suspected infection, arthrocentesis is mandatory for making an accurate diagnosis and also when a swollen and painful joint shows no improvement after $24 \mathrm{~h}$, but only if adequate clotting factor replacement is administered prior to the procedure [20]. Intra-articular injections of corticosteroids may also be useful in selected patients after exclusion of infection, although little evidence is available on their efficacy $[33,34]$. Similarly, the efficacy of other procedures such as joint lavage, alone or associated with steroid injections, is still elusive $[35,36]$.

When recurrent or massive bleeds do not respond to clotting factor replacement, arterial embolization may be considered. Because angiogenesis is one of the leading causes of recurrent hemarthrosis, selective angiographic embolization is one of the treatment options useful in selected cases of synovitis refractory to other treatments, through the reduction of the burden of inflammation that refuels angiogenesis and synovitis and predisposes to recurrent joint bleeding [37]. As soon as pain and swelling improve, physiotherapy should be promptly started to minimize muscle atrophy, prevent joint contractures, and maintain motion range [38]. A program of isometric muscular exercises and stretching is currently considered to be the best option [39].

\section{MANAGEMENT OF CHRONIC ARTHROPATHY}

When chronic synovitis is present, the joint is vulnerable to repeated bleeding, so that the best way to prevent progression to arthropathy is to start early prophylaxis with the deficient coagulation factor. According to the most recent guidelines of the World Federation of Hemophilia (WFH), prophylaxis is defined as the long-term administration of factor replacement at 25-40 IU/kg 2-3 times weekly. In hemophilia A [40], a level of FVIII $>10 \%$ appears to be sufficient to prevent joint damage [37], even though further evidence is required to confirm these data stemming from observational studies $[41,42]$. Primary prophylaxis is defined as a therapeutic regimen started in the absence of documented osteochondral joint disease, as determined by physical examination and/or imaging studies, before the occurrence of the second clinically evident large joint bleeding the age of 3 years. Secondary prophylaxis is a regimen starting after two or more bleedings into large joints and before the onset of joint disease as documented by physical examination and imaging studies. Tertiary prophylaxis is a treatment regimen started in the presence of established joint disease [40]. The earlier prophylaxis is started, the lower is the risk of hemophilic arthropathy. Recently, through the introduction of a non-replacement therapy endowed with an extended half-life such as emicizumab, an even earlier prophylaxis can be offered to patients by means of subcutaneous administration, thus leading to improved adherence coupled with a likelihood of a higher bleeding protection. Comparative studies conducted to evaluate the long-term effects in terms of efficacy and safety of these different prophylaxis approaches are needed.

\section{Local Treatments}

The intra-articular administration of hyaluronic acid is a conservative treatment shown to be effective in osteoarthritis owing to its capability to provide joint lubrication, shock absorbance, and anti-inflammatory analgesic and 
chondroprotective effects [43]. However, evidence on its long-term efficacy in pain reduction and prevention of arthropathy progression is still limited [36, 44-47]. The injection of intra-articular platelet-rich plasma (PRP) has been proposed as an alternative to hyaluronic acid. The rationale for its use is based on its content of growth factors such as plateletderived growth factor, insulin-like growth factor, vascular endothelial growth factor and transforming growth factor beta- 1 but also of proteins such as fibrinogen, fibronectin, vitronectin, and thrombospondin-1 that may play a role in cell migration and matrix remodeling [46]. Other local interventions for recurrent joint bleeding in the presence of chronic synovitis refractory to clotting factor replacement include chemical synoviorthesis with rifampicin or tetracycline and radioisotopic synovectomy, which seems more effective in large joints $[48,49]$.

\section{Rehabilitation}

When arthropathy is already present, the role of physiotherapy is to strengthen muscles in order to stabilize the affected joints. Physical activity includes isometric and isotonic exercises within a comfortable range of movement, proprioception training, and stretching exercises in order to improve muscle and tendon flexibility around the affected joints [39]. Exercises should be tailored based on the individual abilities. In addition, a physiotherapy program including educational sessions and home exercises may improve chronic pain in patients with hemophilia [50]. The beneficial effects of physiotherapy range from the improvement of muscle strength with reduction of bleeding in muscles and joints and subsequent damage progression, to the amelioration of the range of motion, walking ability and balance, and emotional and social well-being $[51,52]$. To improve adherence, prerecorded or telerehabilitation programs with supervised exercise classes may be organized [39] and the introduction of exertional games (exergames or serious games) has been particularly useful in pediatric patients with hemophilia [53].

\section{PHARMACOLOGICAL TREATMENT}

Medications are often needed for the acute and chronic management of pain in hemophilia [20]. The appropriateness of the chosen drug depends on the intensity of the pain. As for other musculoskeletal conditions such as knee osteoarthritis [54], pain-relieving drugs should be used in a crescendo stepwise progression [55], starting from drugs with lower potency but also lower incidence of adverse events such as paracetamol/acetaminophen towards the use of non-steroidal anti-inflammatory drugs (NSAIDs) and opioids [20, 56]. However, in patients with hemophilia, the interference of NSAIDs with platelet function led to the preferred use of selective COX-2 inhibitors (COXIB) owing to their limited adverse effects on platelet function and gastrointestinal tract, and aspirin and other NSAIDs should be avoided. In the field of analgesic management of hemophilic arthropathy, there are few evidence-based studies on efficacy and safety and information mainly stems from small observational studies, case series, and expert opinion. Systemic corticosteroids have a limited efficacy and are not currently recommended in the management of acute and chronic pain in hemophilic arthropathy [20].

\section{Paracetamol/Acetaminophen}

Paracetamol (British approved name, acetaminophen is the US, Canada, and Japan) is an antipyretic drug with peripheral and central antinociceptive effects. Given its wide use and acceptable safety profile [57], it is currently the first-choice medication for mild-to-moderate acute or chronic joint pain in patients with hemophilic arthropathy [20]. Paracetamol exerts a moderate analgesic effect by inhibiting the same cyclooxygenase (COX1) targeted by NSAIDs and aspirin [9]. At the central level, paracetamol also acts by increasing serotonin release [58]. Paracetamol blocks COX for its peroxidase catalytic activity rather than at the COX catalytic site. Thus, the effect of this drug is sensitive to changes in the tissue levels of peroxide and activated leukocytes and platelets 
contain high concentrations of peroxide, thus explaining the poor activity of this drug on inflammation and platelet function. Data of an increased cardiovascular risk and blood pressure are inconclusive following standard doses of paracetamol $[59,60]$, but it appears that its effect on blood pressure is smaller than that of NSAIDs. Although the risk of upper gastrointestinal bleeding is much lower than for NSAIDs, it should be considered for doses greater than $2 \mathrm{~g}$ daily [61]. Paracetamol metabolism envisages glucuronidation and sulphation or oxidation by the cytochrome P450 system, particularly through CYP1E2 which produces the toxic intermediary $N$-acetyl- $p$ benzo-quinone-imine (NAPQI). NAPQI can be conjugated by glutathione $S$-transferase and excreted in the urine, with a wide interindividual and ethnic variation in metabolism [62]. NAPQI production may increase in human immunodeficiency virus (HIV) and hepatitis C virus (HCV) infection, so that liver function should be assessed in order to adjust paracetamol dosage [62].

\section{Non-steroidal Anti-inflammatory Drugs (NSAIDs)}

Non-steroidal anti-inflammatory drugs (NSAIDs) are endowed with analgesic, antipyretic, and anti-inflammatory effects and are widely used to tackle joint pain due to osteoarthritis. They exert action by the non-selective inhibition of prostaglandin synthetase (PGHS), thus blocking the transformation of arachidonic acid in prostaglandins, prostacyclin, and thromboxanes. PGHS has two main isoforms, known as COX-1 and COX-2. COX-1 is expressed constitutively in all cells and is important for platelet aggregation by blocking the upstream pathway to thromboxane A2 (TXA2) production and has also the undesirable effect of reducing gastric mucus secretion, thus resulting in an increased risk of gastrointestinal bleeding.

NSAIDs are also known to increase the risk of cardiovascular events, renal failure, and upper gastrointestinal bleeding. Eyster et al. demonstrated that the GI bleeding risk is significantly increased within one month after NSAID use but not with the use of COXIBs [63]. Considering that patients with hemophilia have an increased risk of upper GI bleeding (up to ten times higher compared to the general population) and that selective COX-2 inhibitors carry a lower risk, COXIBs are the drug of choice and other NSAIDs should be avoided [64], according to guidelines on hemophilia for the management of joint pain in hemophilic arthropathy $[20,40]$. These guidelines describe three levels of analgesic therapy and place COXIBs as a second-line choice after paracetamol (Fig. 1) [20].

Celecoxib [65] and etoricoxib [66] are effective against pain in hemophilic arthropathy when used for up to 30 days for pain control. According to Tsoukas and colleagues [66], celecoxib or etoricoxib did not increase the risk of bleeding compared to placebo, and the safety profile of these drugs in a 6-week case-control study was acceptable. However, the use of COXIBs is associated with an increased risk of cardiovascular events, including death, myocardial infarction, heart failure, and stroke, even though the degree of risk is not higher than that for other non-selective NSAIDs [67]. Therefore, before prescribing COXIBs and NSAIDs in general, each patient should undergo an accurate evaluation of cardiovascular risk factors, particularly in aging persons with hemophilia. Furthermore, as for other NSAIDs, COXIBs should be used with caution in patients with hypertension and renal dysfunction, which is common in patients with hemophilia, even though data from the PRECISION trial indicate a lower incidence of renal adverse events with COXIBs compared with other NSAIDs $[67,68]$.

\section{Opioids}

Opioids in combination with paracetamol are considered a second-line or third-line choice for pain management in patients with hemophilia. Long-term use of opioids as analgesics should be avoided because of the chronic nature of arthropathy in people with severe hemophilia and thus the risk of medication addiction [20]. 


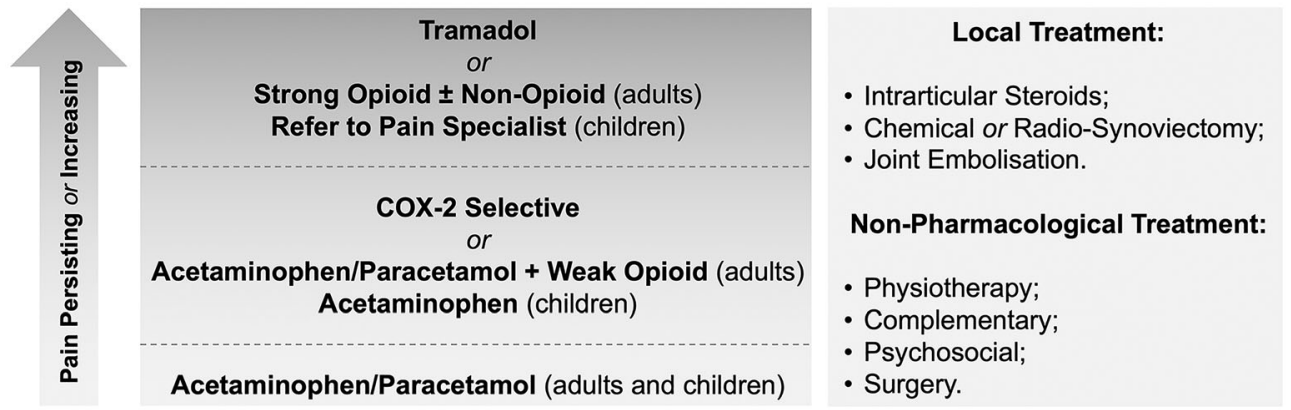

Fig. 1 Pain management strategies in patients with hemophilia. COX-2 cycloxygenase-2. See the WFH Guidelines for the Management of Hemophilia, 3rd edition and Young et al. [20, 56]

Particularly in low-income countries with limited access to replacement therapy, the associated chronic overuse of opioid drugs is a significant problem, which, however, should not be overlooked, even in high-income countries such as the United States of America (USA), where COXIBs have no indication in hemophilia and an opioid overdose crisis is currently ongoing $[69,70]$.

There is no literature on the use of opioids in hemophilic arthropathy, so that evidence stems from studies on osteoarthritis. The recent hemophilia guidelines [20] recommend a gradual initiation of analgesic therapy with opioids, starting with "soft opioids", such as codeine or tramadol in association with paracetamol up to 3-4 times a day. Codeine is a pro-drug requiring hepatic metabolism that produces morphine and the codeine-6-glucuronide, which are active on opioid $\mu$-receptors. There is low-tomoderate evidence stemming from systematic reviews and meta-analyses that analgesic drugs containing a small amount of codeine (e.g., codeine/paracetamol) are effective for acute musculoskeletal pain or in multiple doses for hip joint pain [71]. Tramadol is a synthetic prodrug that requires hepatic metabolism to be turned into $O$-desmethyltramadol. In addition to its analgesic effects on $\mu$-receptors, the active molecule acts as an inhibitor of the reuptake of serotonin and noradrenaline, which seems to determine a direct and indirect analgesic action on central pain transmission. The maximum dose of tramadol should not exceed $400 \mathrm{mg}$ per day and should be even lower when associated with antidepressants that inhibit the reuptake of serotonin and noradrenaline, in order to avoid the risk of the serotonin syndrome [72]. In many studies, the effect of tramadol and the tramadol/paracetamol combination is effective in pain control and safe as gradually titrated [73]. However, in osteoarthritis, the effect of soft opioids, associated or not with paracetamol, offers a smaller analgesic effect than NSAIDs but with fewer side effects in the frame of chronic use. Codeine should not be administered to children under 12 years of age.

In some studies, "strong opioids" are reported to be used more frequently by patients with hemophilia than "soft" ones [74]. Among them, two classes of medicines can be identified [75]. Short-acting opioids (SAOs) have shorter peak time and half-lives and thus are more useful for acute over chronic intermittent pain and in breakthrough pain. This group includes the immediate-release (IR) formulations of morphine, fentanyl and oxycodone, of which there are pharmacological associations with paracetamol. On the other side, the long-acting opioids (LAO) have pharmacokinetic characteristics that favor a longer action duration. They include extended-release (ER), sustained-release (SR), or controlled-release (CR) formulations of oxycodone, fentanyl, and morphine. Systematic reviews and meta-analyses report conflicting data on the use of strong opioids in osteoarthritis [76, 77]. In a systematic review, Megale and colleagues [76] highlighted that the regular use of opioids (from 10 days to 24 weeks, from 10 to $300 \mathrm{mg}$ of oral morphine equivalents) is more often discontinued, not because of analgesic ineffectiveness, but rather 
side effects. Similarly, in a meta-analysis, Fuggle et al. [77] reported an increased risk of gastrointestinal and neurological side effects, albeit mostly minor and non-lethal ones (Table 1).

The use of soft opioids in association with paracetamol or strong opioids alone is effective in reducing pain and improving symptoms. However, these drugs are often discontinued due to unpleasant side effects such as nausea and reduced gastrointestinal transit. In addition, they can lead to abuse, misuse, addiction, and dependence, so that these adverse effects must always be considered when prescribed as analgesics for chronic conditions. The most dangerous side effect is respiratory depression, which requires slow titration in particular in older patients and in those with respiratory ailments. Therefore, the management of acute and chronic pain in patients with hemophilia should be done in collaboration with experts of pain therapy.

\section{SURGICAL TREATMENT}

For hemophilic arthropathy, surgical treatment for pain should be regarded as a last choice when every other intervention has failed. Arthroscopic synovectomy is useful in the case of ankle, elbow, or knee chronic synovitis refractory to factor replacement or when

Table 1 The most frequently reported side effects of opioids

\begin{tabular}{ll}
\hline $\begin{array}{l}\text { System } \\
\text { involved }\end{array}$ & Adverse effect \\
\hline Gastrointestinal & Constipation \\
& Nausea, vomiting \\
& Dyspepsia, gastritis, heartburn \\
& Dry mouth, oral ulceration \\
& Headache \\
& Dizziness \\
& Fatigue, insomnia, weakness, \\
& nervousness \\
\hline
\end{tabular}

radioisotopic or chemical synoviorthesis were unsuccessful [78]. The presence of severe disabling pain is the primary indication for joint replacement, particularly of the knee, thus helping to restore function in case of deranged joint structure involving the cartilage and the subchondral bone associated with pain and disability [79]. Prosthetic surgery or arthrodesis may be useful for advanced disease of the ankle, based on residual function, pain, and patient preference [80].

\section{EMERGING APPROACHES}

Beside the traditional approach to pain, emerging treatments include physical therapies, systemic and local treatments, and lastly behavioral approaches (Table 2). Some of these techniques have already been evaluated in patients with hemophilia, whereas some others have only been validated for osteoarthritic pain.

Physical therapies, such as low-frequency electrotherapy and transcutaneous electrical nerve stimulation (TENS), have been applied for at least 30 years to relieve arthropathic pain in hemophilia [81]. According to the gate control theory, the perception of pain can be modulated by acting on spinal interneurons, with related synaptic inhibition of neurons responsible for the transmission of pain information. TENS inhibits peripheral nerves involved in nociceptive transmission, although also the release of neuropeptides such as endorphins could be a mechanism of action. Another physical therapy option is the application of neuromuscular electrical stimulation (NEMS), which improves muscular strength and breaks the vicious circle of pain leading to reduced motility and worsening of arthropathy [82].

Low-level laser therapy (LLLT) envisages the application of light in the range of $1-500 \mathrm{~mW}$, thus promoting tissue regeneration, inflammation modulation, and pain relief enhancements. Pulsed electromagnetic field (PEMF) was reported to be effective in reducing pain, healing ulcers, promoting bone healing, and treating osteoarthritis and musculoskeletal inflammatory diseases. Eid et al. recently conducted a study on 30 children with hemophilia 
Table 2 Emerging approaches in hemophilia

\begin{tabular}{|c|c|c|}
\hline Classification & Treatment & Evidence in hemophilia \\
\hline \multirow[t]{8}{*}{$\begin{array}{l}\text { Physical } \\
\text { therapies }\end{array}$} & $\begin{array}{l}\text { Transcutaneous electrical nerve } \\
\text { stimulation (TENS) }\end{array}$ & $\begin{array}{l}\text { Roche et al., Pain. 1985;21(1):43-8 } \\
\text { De la Corte-Rodriguez, Rodriguez-Merchan, Blood } \\
\text { Coagulation and Fibrinolysis. } 2012 \text { Sep;24(1):1-9 }\end{array}$ \\
\hline & $\begin{array}{l}\text { Neuromuscular electrical stimulation } \\
\text { (NEMS) }\end{array}$ & No evidence \\
\hline & Spinal cord stimulation (SCS) & No evidence \\
\hline & Low-level laser therapy (LLLT) & Eid et al., Lasers Med Sci. 2015 Nov;30(8):2179-87 \\
\hline & Pulsed electromagnetic field (PEMF) & Eid et al., Lasers Med Sci. 2015 Nov;30(8):2179-87 \\
\hline & Acupuncture & Oliveira et al., Haemophilia. 2020 Nov;26(6):e315-e22 \\
\hline & Scrambler therapy & No evidence \\
\hline & Kinesiotaping & $\begin{array}{l}\text { Azab et al., Journal of Musculoskeletal and Neuronal } \\
\text { Interactions. 2020;20(2):256-64 }\end{array}$ \\
\hline \multirow[t]{2}{*}{$\begin{array}{l}\text { Local } \\
\text { treatment }\end{array}$} & $\begin{array}{l}\text { Transplantation with bone marrow- } \\
\text { derived mesenchymal stem cell }\end{array}$ & Buda et al., Cartilage. 2015 Jul;6(3):150-5 \\
\hline & Intra-articular injections of ozone & No evidence \\
\hline \multirow{3}{*}{$\begin{array}{l}\text { Systemic } \\
\text { treatment }\end{array}$} & Endocannabinoids & No evidence \\
\hline & Antidepressants and anticonvulsants & Stromer et al., Wien Klin Wochenschr. 2021 Mar 4 \\
\hline & $\begin{array}{l}\text { Iron chelators, anti-inflammatories, anti- } \\
\text { fibrinolytics }\end{array}$ & Pulles et al., Pharmacol Res. 2017 Jan;115:192-9 \\
\hline \multirow{2}{*}{$\begin{array}{l}\text { Behavioral } \\
\text { approaches }\end{array}$} & Mindfulness & No evidence \\
\hline & Cognitive behavioral therapy & García-Dasí et al., Haemophilia. 2021 May; 27 (3), e357-e367 \\
\hline
\end{tabular}

comparing and investigating the effects of LLLT and PEMF. Both treatments led to pain improvement and swelling reduction, increased range of motion, and improved physical fitness after 12 weeks of therapy [83].

Another promising approach for the management of chronic pain is spinal cord stimulation (SCS), which has its roots in the concept of gate control theory. SCS has already been applied with beneficial effects in chronic neuropathic pain [84]. The SCS works through the application of tonic $40-60-\mathrm{Hz}$ stimulation that activates dorsal columns in order to interfere with the transmission of nociceptive impulses.
Concern exists about the possible development of epidural hematoma but this procedure may be safely carried out under appropriate prophylaxis. A spinal cord stimulator was placed with no bleeding in a patient with von Willebrand disease type 1 in order to treat a complex regional pain syndrome [85]. Nevertheless, solid evidence on the efficacy of SCS in hemophilic arthropathic pain is missing.

The paradigm of the gate control theory of pain has been recently overturned by the appearance of scrambler therapy. Scrambler therapy is an electro-analgesia vehiculated by five artificial nerves that transmit "non-pain" 
information by C-fiber surface receptors. This therapy is apparently able to interfere with the plasticity of the pain system and induce its regression by providing "no pain" information repeated over time [86, 87]. Scrambler therapy has been episodically applied for the treatment of osteoarthritis pain, and it may be a promising physical therapy for the future of hemophilic chronic pain, but solid evidence is currently lacking.

Kinesiotaping is a novel technique that envisages the application of an elastic, adhesive bandage on the skin overlying the injured tissues that can stretch up to $140 \%$ of its original size, supporting muscles and joints and improving blood circulation and lymphatic drainage. It has been applied to adolescents with hemophilia as an adjunctive therapy to reduce lower back pain, improve back muscle endurance, and enhance functional capacity. In the future, it may be considered in addition to systemic treatment to improve recovery after acute hemarthrosis [88].

A few reports on the adoption of local regenerative medicine in hemophilia are available. In a small group of patients, synovectomy and arthroscopic debridement of the ankle were combined with autologus bone marrow-derived mesenchymal stem cell implant and plateletrich fibrin showed improvement of symptoms, functional ability, and signs of regeneration of cartilage and bone after a mean follow-up of 2 years [89].

Medical ozone is composed by a mixture of oxygen and ozone gas with unique mechanisms of action, including oxygenation, immune modulation, and anti-inflammatory properties. Although the exact biochemical mechanisms of action of its intra-articular injection are still unclear, there is increasing evidence that this therapy might be effective for the treatment of knee osteoarthritis. In a recent review of the literature comprising five randomized clinical trials and 428 subjects, intra-articular injections of ozone resulted superior to placebo and in relieving knee pain in a follow-up of 6 months [90]. There is no evidence available in pain management in hemophilic arthropathy.

One of the goals in tackling pain in hemophilic arthropathy is to interrupt pain chronicization. Repeated acute pain during hemarthrosis together with chronic pain due to arthropathy may lead to sensitization of noxious stimuli vehicled by peripheric nerves and to an increased susceptibility to non-painful stimuli. If central sensitization is suspected, antidepressants and anticonvulsants should be considered as comedications. Caution must be used when prescribing selective serotonin reuptake inhibitors (SSRI) because of their activity on platelet serotonin reuptake and related inhibition of platelet aggregation with an increased risk of bleeding [91]. The endocannabinoid system is a promising target for osteoarthritis pain [92]. The role of cannabinoids in hemophilic arthropathy has not been studied yet, so in the future these molecules may be used to tackle chronic pain management. Recently, Pulles et al. described the emerging roles of disease-modifying therapies in hemophilic arthropathy: iron chelators, antiinflammatories, anti-fibrinolytics, and bone remodeling agents have been predominantly studied in a preclinical setting, paving the way for future approaches based on the pathogenesis of the hemophilic arthropathy [93].

Chronic pain management also envisages enhanced self-management, and behavioral and motivational changes. Among these techniques, mindfulness exercises, cognitive behavioral approaches, and biofeedback have been proposed in hemophilia [91]. Cognitive behavioral therapy has been studied in a prospective two-arm single-blind parallel-group controlled trial showing to be effective in improving chronic pain, quality of life, and emotional status of patients with hemophilia [94].

\section{CONCLUSIONS}

In conclusion, a number of different drugs are available for pain control in hemophilia and many novel approaches are gaining interest. Standardization in the choice of treatment for pain is ongoing. In the meantime, an appropriate evaluation by a multidisciplinary team involving hematologists, orthopedic surgeons, rheumatologists, and physiotherapists, and the 
use of the safest drugs at the lowest effective dosage and for periods as short as possible will allow reducing the incidence of adverse effects.

\section{ACKNOWLEDGEMENTS}

We thank Prof. Pier Mannuccio Mannucci for the useful discussion on the contents of the manuscript and the revision and Dr. Luigi Flaminio Ghilardini for figure editing.

Funding. This study was supported by Ricerca Corrente 2021 funding from the Italian Ministry of Health. No funding or sponsorship was received for the publication of this article.

Authorship. All named authors meet the International Committee of Medical Journal Editors (ICMJE) criteria for authorship for this article, take responsibility for the integrity of the work as a whole, and have given their approval for this version to be published.

Author Contributions. All authors contributed to concept and design, literature search, manuscript writing, and reviewing.

Disclosures. Roberta Gualtierotti, Francesco Tafuri, Sara Arcudi, Pier Luigi Solimeno, Jacopo Acquati, Laura Landi, Flora Peyvandi have nothing to disclose.

Compliance with Ethics Guidelines. This article is based on previously conducted studies and does not contain any new studies with human participants or animals performed by any of the authors.

Open Access. This article is licensed under a Creative Commons Attribution-NonCommercial 4.0 International License, which permits any non-commercial use, sharing, adaptation, distribution and reproduction in any medium or format, as long as you give appropriate credit to the original author(s) and the source, provide a link to the Creative Commons licence, and indicate if changes were made. The images or other third party material in this article are included in the article's Creative Commons licence, unless indicated otherwise in a credit line to the material. If material is not included in the article's Creative Commons licence and your intended use is not permitted by statutory regulation or exceeds the permitted use, you will need to obtain permission directly from the copyright holder. To view a copy of this licence, visit http://creativecommons.org/licenses/by$\mathrm{nc} / 4.0 /$.

\section{REFERENCES}

1. Stonebraker JS, Bolton-Maggs PH, Michael Soucie J, Walker I, Brooker M. A study of variations in the reported haemophilia $B$ prevalence around the world. Haemophilia. 2012;18(3):e91-4.

2. Bolton-Maggs PH, Pasi KJ. Haemophilias A and B. Lancet. 2003;361(9371):1801-9.

3. Di Minno MN, Ambrosino P, Franchini M, Coppola A, Di Minno G. Arthropathy in patients with moderate hemophilia a: a systematic review of the literature. Semin Thromb Hemost. 2013;39(7): 723-31.

4. Aronstam A, Rainsford SG, Painter MJ. Patterns of bleeding in adolescents with severe haemophilia A. Br Med J. 1979;1(6161):469-70.

5. Jean-Baptiste G, De Ceulaer K. Osteoarticular disorders of haematological origin. Best Pract Res Clin Rheumatol. 2000;14(2):307-23.

6. Blanchette VS, Key NS, Ljung LR, Manco-Johnson MJ, van den Berg HM, Srivastava A, et al. Definitions in hemophilia: communication from the SSC of the ISTH. J Thromb Haemost. 2014;12(11): 1935-9.

7. Gualtierotti R, Solimeno LP, Peyvandi F. Hemophilic arthropathy: current knowledge and future perspectives. J Thromb Haemost. 2021;19(9): 2112-21.

8. Roosendaal G, van Rinsum AC, Vianen ME, van den Berg HM, Lafeber FP, Bijlsma JW. Haemophilic arthropathy resembles degenerative rather than inflammatory joint disease. Histopathology. 1999;34(2):144-53.

9. Valentino LA. Blood-induced joint disease: the pathophysiology of hemophilic arthropathy. J Thromb Haemost. 2010;8(9):1895-902. 
10. Shapiro AD, Donfield SM, Lynn HS, Cool VA, Stehbens JA, Hunsberger SL, et al. Defining the impact of hemophilia: the academic achievement in children with hemophilia study. Pediatrics. 2001;108(6):e105.

11. Mahlangu J, Oldenburg J, Callaghan MU, Shima M, Mancuso ME, Trask P, et al. Health-related quality of life and health status in persons with haemophilia A with inhibitors: a prospective, multicentre, non-interventional study (NIS). Haemophilia. 2019;25(3):382-91.

12. O'Hara J, Walsh S, Camp C, Mazza G, Carroll L, Hoxer $\mathrm{C}$, et al. The impact of severe haemophilia and the presence of target joints on health-related quality-of-life. Health Qual Life Outcomes. 2018;16(1):84.

13. Zhou ZY, Koerper MA, Johnson KA, Riske B, Baker JR, Ullman $M$, et al. Burden of illness: direct and indirect costs among persons with hemophilia A in the United States. J Med Econ. 2015;18(6):457-65.

14. Solimeno LP, Pasta G. Knee and ankle arthroplasty in hemophilia. J Clin Med. 2017;6(11):107.

15. Rodriguez-Merchan EC, De la Corte-Rodriguez H. Pain management in people with hemophilia in childhood and young adulthood. Expert Rev Hematol. 2021;14(6):525-35.

16. Elander J. A review of evidence about behavioural and psychological aspects of chronic joint pain among people with haemophilia. Haemophilia. 2014;20(2):168-75.

17. Timmer MA, Pisters MF, de Kleijn P, Veenhof C, Laros-van Gorkom BA, Kruip MJ, et al. How do patients and professionals differentiate between intra-articular joint bleeds and acute flare-ups of arthropathy in patients with haemophilia? Haemophilia. 2016;22(3):368-73.

18. Ceponis A, Wong-Sefidan I, Glass CS, von Drygalski A. Rapid musculoskeletal ultrasound for painful episodes in adult haemophilia patients. Haemophilia. 2013;19(5):790-8.

19. Elander J, Richardson C, Morris J, Robinson G, Schofield MB. Motivational and behavioural models of change: a longitudinal analysis of change among men with chronic haemophilia-related joint pain. Eur J Pain. 2017;21(8):1384-96.

20. Srivastava A, Santagostino E, Dougall A, Kitchen S, Sutherland M, Pipe SW, et al. WFH guidelines for the management of hemophilia, $3^{\text {rd }}$ edition. Haemophilia. 2020;26(Suppl 6):1-158.

21. Oldenburg J, Mahlangu JN, Kim B, Schmitt C, Callaghan MU, Young $G$, et al. Emicizumab prophylaxis in hemophilia A with inhibitors. N Engl J Med. 2017;377(9):809-18.

22. Mahlangu J, Oldenburg J, Paz-Priel I, Negrier C, Niggli M, Mancuso ME, et al. Emicizumab prophylaxis in patients who have hemophilia a without inhibitors. N Engl J Med. 2018;379(9):811-22.

23. Collins PW, Liesner R, Makris M, Talks K, Chowdary $\mathrm{P}$, Chalmers E, et al. Treatment of bleeding episodes in haemophilia A complicated by a factor VIII inhibitor in patients receiving Emicizumab. Interim guidance from UKHCDO inhibitor working party and executive committee. Haemophilia. 2018;24(3):344-7.

24. Castaman G, Santoro C, Coppola A, Mancuso ME, Santoro RC, Bernardini S, et al. Emergency management in patients with haemophilia A and inhibitors on prophylaxis with emicizumab: AICE practical guidance in collaboration with SIBioC, SIMEU, SIMEUP, SIPMeL and SISET. Blood Transfus = Trasfus del Sangue. 2020;18(2):143-51.

25. d'Young AI. Domiciliary application of CryoCuff in severe haemophilia: qualitative questionnaire and clinical audit. Haemophilia. 2008;14(4):823-7.

26. Hermans C, De Moerloose P, Fischer K, Holstein K, Klamroth R, Lambert T, et al. Management of acute haemarthrosis in haemophilia A without inhibitors: literature review, European survey and recommendations. Haemophilia. 2011;17(3):383-92.

27. Müller S, Kurth AA, Hovy L. Conservative treatment measures in hemophilic arthropathy. Der Orthop. 1999;28(4):347-55.

28. Rodriguez-Merchan EC. Treatment of musculoskeletal pain in haemophilia. Blood Rev. 2018;32(2):116-21.

29. van Vulpen LF, van Meegeren ME, Roosendaal G, Jansen NW, van Laar JM, Schutgens RE, et al. Biochemical markers of joint tissue damage increase shortly after a joint bleed; an explorative human and canine in vivo study. Osteoarthr Cartil. 2015;23(1):63-9.

30. van Meegeren MER, Roosendaal G, van Veghel K, Mastbergen SC, Lafeber FPJG. A short time window to profit from protection of blood-induced cartilage damage by IL-4 plus IL-10. Rheumatology. 2013;52(9):1563-71.

31. De la Corte-Rodriguez H, Rodriguez-Merchan EC, Alvarez-Roman MT, Martin-Salces M, Romero-Garrido JA, Jimenez-Yuste $\mathrm{V}$. Accelerating recovery from acute hemarthrosis in patients with hemophilia: the role of joint aspiration. Blood Coagul Fibrinolysis Int J Haemost Thromb. 2019;30(3): 111-9. 
32. Rodriguez-Merchan EC, De la Corte-Rodriguez H, Jimenez-Yuste V. Joint aspiration of acute tense knee haemarthroses in adult haemophilia A patients. Thromb Res. 2013;132(6):778-9.

33. Manners PJ, Price P, Buurman D, Lewin B, Smith B, Cole $\mathrm{CH}$. Joint aspiration for acute hemarthrosis in children receiving factor VIII prophylaxis for severe hemophilia: 11-year safety data. J Rheumatol. 2015;42(5):885-90.

34. Rodríguez-Merchán EC, Villar A, Orbe A, Magallón M. Intra-articular methylprednisolone therapy in chronic hemophilic synovitis of the knee. Rev Clin Esp. 1994;194(6):480-2.

35. Rodriguez-Merchan EC, Valentino LA. Joint lavage followed by intra-articular injection of hyaluronic acid and/or corticosteroids in patients with severe hemophilic arthropathy of the knee: is this intervention really effective? Expert Rev Hematol. 2018;11(6):449-54.

36. Rezende MU, Andrusaitis FR, Silva RT, Okazaki E, Carneiro JD, Campos GC, et al. Joint lavage followed by viscosupplementation and triamcinolone in patients with severe haemophilic arthropathy: objective functional results. Haemophilia. 2017;23(2):e105-15.

37. Obaji S, Jones C, Yates A, Gordon A, Wood A, Alikhan R, et al. Selective angiographic embolization for recurrent elbow and knee haemarthroses in haemophilia: a retrospective case series. Haemophilia. 2015;21(3):e226-8.

38. Mejia-Carvajal C, Hakobyan N, Enockson C, Valentino LA. The impact of joint bleeding and synovitis on physical ability and joint function in a murine model of haemophilic synovitis. Haemophilia. 2008;14(1):119-26.

39. Boccalandro E, Mancuso ME, Riva S, Pisaniello DM, Ronchetti F, Santagostino E, et al. Ageing successfully with haemophilia: a multidisciplinary programme. Haemophilia. 2018;24(1):57-62.

40. Srivastava A, Brewer AK, Mauser-Bunschoten EP, Key NS, Kitchen S, Llinas A, et al. Guidelines for the management of hemophilia. Haemophilia. 2013;19(1):e1-47.

41. Peyvandi F, Berger K, Seitz R, Hilger A, Hecquet ML, Wierer M, et al. Kreuth V initiative: European consensus proposals for treatment of haemophilia using standard products, extended half-life coagulation factor concentrates and non-replacement therapies. Haematologica. 2020;105(8):2038.

42. Den Uijl IEM, Fischer K, van der Bom JG, Grobbee DE, Rosendaal FR, Plug I. Analysis of low frequency bleeding data: the association of joint bleeds according to baseline FVIII activity levels. Haemophilia. 2011;17(1):41-4.

43. Pavelka K, Uebelhart D. Efficacy evaluation of highly purified intra-articular hyaluronic acid (Si$\operatorname{novial}(\AA)$ ) vs Hylan G-F20 (Synvisc( $(\circledR)$ ) in the treatment of symptomatic knee osteoarthritis. A double-blind, controlled, randomized, parallelgroup non-inferiority study. Osteoarthr Cartil. 2011;19(11):1294-300.

44. Carulli C, Rizzo AR, Innocenti M, Civinini R, Castaman G, Innocenti M. Viscosupplementation in symptomatic haemophilic arthropathy of the knee and ankle: experience with a high molecular weight hyaluronic acid. Haemophilia. 2020;26(4): e198-200.

45. Liou IH, Lu LY, Lin KY, Yu LH, Yang SM, Tsai MY, et al. Combined intra-articular injections of hyaluronic acid and platelet-rich plasma for the treatment of haemophilic arthropathy: a case series study. Haemophilia. 2020;27(2):e291-4.

46. Li TY, Wu YT, Chen LC, Cheng SN, Pan RY, Chen YC. An exploratory comparison of single intra-articular injection of platelet-rich plasma vs hyaluronic acid in treatment of haemophilic arthropathy of the knee. Haemophilia. 2019;25(3): 484-92.

47. Rodriguez-Merchan EC. Intra-articular injections of hyaluronic acid (viscosupplementation) in the haemophilic knee. Blood Coagul Fibrinolysis Int J Haemost Thromb. 2012;23(7):580-3.

48. Rodriguez-Merchan EC, De la Corte-Rodriguez H, Jimenez-Yuste V. Radiosynovectomy in haemophilia: long-term results of 500 procedures performed in a 38-year period. Thromb Res. 2014;134(5): 985-90.

49. Ali T, Abou Fakher FH, Schved JF. Chemical vs radioactive synoviorthesis for treatment of chronic haemophilic synovitis: Syrian experience. Haemophilia. 2016;22(6):e573-5.

50. Cuesta-Barriuso R, Torres-Ortuño A, Nieto-Munuera J, López-Pina JA. Effectiveness of an educational physiotherapy and therapeutic exercise program in adult patients with hemophilia: a randomized controlled trial. Arch Phys Med Rehabil. 2017;98(5): 841-8.

51. Schäfer GS, Valderramas S, Gomes AR, Budib MB, Wolff ÁL, Ramos AA. Physical exercise, pain and musculoskeletal function in patients with haemophilia: a systematic review. Haemoph Off J World Fed Hemoph. 2016;22(3):e119-29.

52. Negrier C, Seuser A, Forsyth A, Lobet S, Llinas A, Rosas $\mathrm{M}$, et al. The benefits of exercise for patients 
with haemophilia and recommendations for safe and effective physical activity. Haemoph Off J World Fed Hemoph. 2013;19(4):487-98.

53. Boccalandro EA, Begnozzi V, Mannucci PM. Intelligent game engines for home exercises (exergames) in boys with haemophilia. Haemophilia. 2020;27(1):e151-4.

54. Bannuru RR, Osani MC, Vaysbrot EE, Arden NK, Bennell K, Bierma-Zeinstra SMA, et al. OARSI guidelines for the non-surgical management of knee, hip, and polyarticular osteoarthritis. Osteoarthr Cartil. 2019;27(11):1578-89.

55. Ventafridda V, Saita L, Ripamonti C, De Conno F. WHO guidelines for the use of analgesics in cancer pain. Int J Tissue React. 1985;7(1):93-6.

56. Young G, Tachdjian R, Baumann K, Panopoulos G. Comprehensive management of chronic pain in haemophilia. Haemophilia. 2014;20(2):e113-20.

57. Towheed TE, Maxwell L, Judd MG, Catton M, Hochberg MC, Wells G. Acetaminophen for osteoarthritis. Cochrane Database Syst Rev. 2006;25(1):Cd004257.

58. Hamurtekin Y, Nouilati A, Demirbatir C, Hamurtekin $\mathrm{E}$. The contribution of serotonergic receptors and nitric oxide systems in the analgesic effect of acetaminophen: an overview of the last decade. Turk J Pharm Sci. 2020;17(1):119-26.

59. Dawson J, Fulton R, McInnes GT, Morton R, Morrison D, Padmanabhan S, et al. Acetaminophen use and change in blood pressure in a hypertensive population. J Hypertens. 2013;31(7):1485-90 (Discussion 90).

60. Gualtierotti R, Zoppi A, Mugellini A, Derosa G, D'Angelo A, Fogari R. Effect of naproxen and acetaminophen on blood pressure lowering by ramipril, valsartan and aliskiren in hypertensive patients. Expert Opin Pharmacother. 2013;14(14):1875-84.

61. González-Pérez A, Sáez ME, Johansson S, Nagy P, García Rodríguez LA. Risk factors associated with uncomplicated peptic ulcer and changes in medication use after diagnosis. PLoS ONE. 2014;9(7): e101768.

62. van Veen JJ, Gleeson DC, Makris M. Paracetamol/ acetaminophen usage in haemophilia: more caution needed? Haemophilia. 2008;14(3):434-5.

63. Eyster ME, Asaad SM, Gold BD, Cohn SE, Goedert JJ. Upper gastrointestinal bleeding in haemophiliacs: incidence and relation to use of non-steroidal antiinflammatory drugs. Haemophilia. 2007;13(3): 279-86.
64. Arachchillage DRJ, Makris M. Choosing and using non-steroidal anti-inflammatory drugs in haemophilia. Haemophilia. 2016;22(2):179-87.

65. Rattray B, Nugent DJ, Young G. Celecoxib in the treatment of haemophilic synovitis, target joints, and pain in adults and children with haemophilia. Haemophilia. 2006;12(5):514-7.

66. Tsoukas C, Eyster ME, Shingo S, Mukhopadhyay S, Giallella KM, Curtis SP, et al. Evaluation of the efficacy and safety of etoricoxib in the treatment of hemophilic arthropathy. Blood. 2006;107(5): 1785-90.

67. Nissen SE, Yeomans ND, Solomon DH, Lüscher TF, Libby P, Husni ME, et al. Cardiovascular safety of celecoxib, naproxen, or ibuprofen for arthritis. N Engl J Med. 2016;375(26):2519-29.

68. Yeomans ND, Graham DY, Husni ME, Solomon DH, Stevens T, Vargo J, et al. Randomised clinical trial: gastrointestinal events in arthritis patients treated with celecoxib, ibuprofen or naproxen in the PRECISION trial. Aliment Pharmacol Ther. 2018;47(11): 1453-63.

69. Ciccarone D. The triple wave epidemic: Supply and demand drivers of the US opioid overdose crisis. Int J Drug Policy. 2019;71:183-8.

70. Rudd RA, Aleshire N, Zibbell JE, Gladden RM. Increases in drug and opioid overdose deaths-United States, 2000-2014. MMWR Morb Mortal Wkly Rep. 2016;64(50-51):1378-82.

71. Abdel Shaheed C, Maher CG, McLachlan AJ. Efficacy and safety of low-dose codeine-containing combination analgesics for pain: systematic review and meta-analysis. Clin J Pain. 2019;35(10):836-43.

72. Humphries TJ, Kessler CM. Managing chronic pain in adults with haemophilia: current status and call to action. Haemophilia. 2015;21(1):41-51.

73. Cepeda MS, Camargo F, Zea C, Valencia L. Tramadol for osteoarthritis. Cochrane Database Syst Rev. 2006;19(3):Cd005522.

74. Witkop M, Lambing A, Kachalsky E, Divine G, Rushlow D, Dinnen J. Assessment of acute and persistent pain management in patients with haemophilia. Haemophilia. 2011;17(4):612-9.

75. Argoff CE, Silvershein DI. A comparison of longand short-acting opioids for the treatment of chronic noncancer pain: tailoring therapy to meet patient needs. Mayo Clin Proc. 2009;84(7):602-12.

76. Megale RZ, Deveza LA, Blyth FM, Naganathan V, Ferreira PH, McLachlan AJ, et al. Efficacy and safety of oral and transdermal opioid analgesics for 
musculoskeletal pain in older adults: a systematic review of randomized, placebo-controlled trials. J Pain Off J Am Pain Soc. 2018;19(5):475.e1-e24.

77. Fuggle N, Curtis E, Shaw $S$, Spooner L, Bruyère $\mathrm{O}$, Ntani G, et al. Safety of opioids in osteoarthritis: outcomes of a systematic review and meta-analysis. Drugs Aging. 2019;36(Suppl 1):129-43.

78. Yoon KH, Bae DK, Kim HS, Song SJ. Arthroscopic synovectomy in haemophilic arthropathy of the knee. Int Orthop. 2005;29(5):296-300.

79. Rodríguez-Merchán EC. The role of orthopaedic surgery in haemophilia: current rationale, indications and results. EFORT Open Rev. 2019;4(5): 165-73.

80. Rodriguez-Merchan EC. Management of hemophilic arthropathy of the ankle. Cardiovasc Hematol Disord Drug Targets. 2017;17(2):111-8.

81. Roche PA, Gijsbers K, Belch JJ, Forbes CD. Modification of hemophilic haemorrhage pain by transcutaneous electrical nerve stimulation. Pain. 1985;21(1):43-8.

82. Gomis M, Gonzalez LM, Querol F, Gallach JE, TocaHerrera JL. Effects of electrical stimulation on muscle trophism in patients with hemophilic arthropathy. Arch Phys Med Rehabil. 2009;90(11): 1924-30.

83. Eid MA, Aly SM. LASER versus electromagnetic field in treatment of hemarthrosis in children with hemophilia. Lasers Med Sci. 2015;30(8):2179-87.

84. Sdrulla AD, Guan Y, Raja SN. Spinal cord stimulation: clinical efficacy and potential mechanisms. Pain Pract. 2018;18(8):1048-67.

85. Singla P, Kohan LR. Spinal cord stimulator placement in patient with von Willebrand disease: a case report. A A Pract. 2020;14(5):149-51.

86. Majithia N, Smith TJ, Coyne PJ, Abdi S, Pachman DR, Lachance D, et al. Scrambler therapy for the management of chronic pain. Support Care Cancer. 2016;24(6):2807-14.
87. Marineo G. Inside the scrambler therapy, a noninvasive treatment of chronic neuropathic and cancer pain: from the gate control theory to the active principle of information. Integr Cancer Ther. 2019;18:1-17.

88. Azab AR, Elnaggar RK, Diab RH, Moawd SA. Therapeutic value of Kinesio taping in reducing lower back pain and improving back muscle endurance in adolescents with hemophilia. J Musculoskelet Neuronal Interact. 2020;20(2):256-64.

89. Buda R, Cavallo M, Castagnini F, Cenacchi A, Natali $S$, Vannini F, et al. Treatment of hemophilic ankle arthropathy with one-step arthroscopic bone marrow-derived cells transplantation. Cartilage. 2015;6(3):150-5.

90. Raeissadat SA, Tabibian E, Rayegani SM, RahimiDehgolan S, Babaei-Ghazani A. An investigation into the efficacy of intra-articular ozone (O2-O3) injection in patients with knee osteoarthritis: a systematic review and meta-analysis. J Pain Res. 2018;11:2537-50.

91. Stromer W, Pabinger I, Ay C, Crevenna R, Donnerer $\mathrm{J}$, Feistritzer C, et al. Pain management in hemophilia: expert recommendations. Wien Klin Wochenschr. 2021. https://doi.org/10.1007/ s00508-020-01798-4.

92. O'Brien M, McDougall JJ. Cannabis and joints: scientific evidence for the alleviation of osteoarthritis pain by cannabinoids. Curr Opin Pharmacol. 2018;40:104-9.

93. Pulles AE, Mastbergen SC, Schutgens RE, Lafeber FP, van Vulpen LF. Pathophysiology of hemophilic arthropathy and potential targets for therapy. Pharmacol Res. 2017;115:192-9.

94. García-Dasí M, Pérez-Alenda S, Carrasco JJ, Marques-Sule E, Aguilar-Rodríguez M, Moreno-Segura $\mathrm{N}$, et al. Effects of a non-pharmacological approach for chronic pain management in patients with haemophilia: efficacy of cognitive-behavioural therapy associated with physiotherapy. Haemophilia. 2021;27(3):e357-67. 